\title{
MEASURING LOGISTICS PERFORMANCE FOR COMPETITIVENESS- A CASE STUDY OF AUTOMOTIVE CONNECTION SYSTEMS COMPANY, KERALA, INDIA
}

\author{
C. Sengottuvelu \\ Professor, Department of Management Studies (PG), \\ Acharya Bangalore B School (ABBS), Bengaluru, Karnataka, India \\ V.P. Sriram \\ Associate Professor, Department of Management Studies (PG), \\ Acharya Bangalore B School (ABBS), Bengaluru, Karnataka, India.
}

\begin{abstract}
A company having implemented a logistics system must continually monitor and evaluate its effectiveness. Similarly, a company may utilize several different methods to measure logistics performance. This study was conducted at Automotive System Connections Ltd., in Kerala, India. This company's warehouse handles 720 traded parts out of which $96 \%$ comes from intercompany basis and the remaining $4 \%$ of items comes from their local suppliers located in India. It was found that the company moves $98 \%$ of traded parts by road / surface transportation mode and the remaining only by air cargo mode. These parts are supplied to original equipment manufacturers in India. So, logistics performance measurement was considered an important area for this research. Twelve important metrics were selected for measurements and three years data collected from their main information report (MIR), returns, and reports followed by interview method with senior executives of the company. This company is in the process of implementing lean approach in their warehouse operations. This company should more focus on some of the metrics like inventory turnover ratio, overall customer satisfaction, total logistics cost, and capacity of warehouse vs space utilization. This company should focus on Full Truck Load (FTL) rather than Less Truck Load (LTL) by consolidation and collaboration with Third Party Logistics Service providers (3PL). This company should also change incoterm to Freight on Board (FOB) / Free along Ship side (FAS) from Ex-Works.
\end{abstract}


Measuring Logistics Performance for Competitiveness - A Case Study of Automotive Connection Systems Company, Kerala, India

Key words: Logistics Metrics, Logistics Performance Measurements, Lean Approach, Warehouse Operations.

Cite this Article: C. Sengottuvelu and V.P. Sriram, Measuring Logistics Performance for Competitiveness - A Case Study of Automotive Connection Systems Company, Kerala, India, International Journal of Management, 11(12), 2020, pp 278-287.

http://iaeme.com/Home/issue/IJM?Volume=11\&Issue=12

\section{INTRODUCTION}

Performance measurements and metrics play a vital role in achieving organizational objectives. It is more so in measuring logistics performance. Logistics is that part of supply chain management that plans, implements, and controls the efficient, effective forward and reverse flow and storage of goods, services and related information between the point of origin and the point of consumption in order to meet customers' requirements.

In recent times, customers' expectations are increasing in terms of quick delivery, short lead time, lowest price and customization. To achieve this, companies should know that what is the right type of supply chain for their products? Companies should also know demand for their products i.e functional products and innovative products. So, the companies should develop physically efficient supply chains for functional products and market responsive products for innovative products (Fisher, 1997). Again, there is a trade-off between cost and responsiveness. Supply chain strategies should support and right level of strategic fit should be established in the organization. Strategic fit requires that all functions within a stages in the supply chain target the same goal, one that is consistent with customer needs (Sunil Chopra, Peter Meindle, and D.V.Kalra, 2013).

Logistics is one of the essential component in any supply chain besides, sourcing \& procurement, manufacturing, distribution, and reverse logistics (return of products). To improve the performance of logistics, measurement is very important. Company are constantly striving for gaining competitive advantage in business, so, logistical operations are one such area. Competitive advantage can be leveraged through identifying competitive priorities. Competitive priorities are defined as the dimensions that a firm's production system must possess to support the demands of the markets in which the firm wishes to compete. Six important criteria which act as competitive priorities are quality, cost, delivery, flexibility, customer focus and know-how (Awwad, Alkhattab and Anchor, 2013, Gaither and Frazier, 2015).

Peter Drucker (1954) wrote 'What gets measured gets managed". According to Ridgway (1956) 'What get measured gets management- even when it's pointless to measure and manage it, and even if it harms the purpose of the organization to do so'. Not every thing that matters can be measured. Not everything that we can measure matters'. Different types of measurement tools are used to measure the performance of logistics and supply chains. The basic for competing in the new era will be: product innovation multiplied with process innovation. But, in today's market place the ordering -winning criteria are most likely to be service-based then product -based (M. Christopher, 2003). According to Bloomberg, LeMay and Hanna (2005) the areas of performance measurements in logistics should cover: labour measures, cost measures, equipment measures, energy measures, transit time measure, utilization measure and facility measure. Coyle, Bardi and Langley Jr. (2006) have suggested that the performance measurement in logistics should focus on cost criteria, cost output, productivity criteria, service criteria and business due to stock out.

The important tools are: i. SCOR metrics, ii. Logistics Council metrics, iii. Balanced Score Card and iv. Economic Value Added and v. Activity Based Costing. Most of these 
measurements focus on financial aspects and operational aspects. SCOR has developed more than 200 metrics for performance measurements. Some of the metrics are industry specific, so, choosing a right type of metrics is very important. According to Raja (2020) the important logistics metrics are shown in table 1.

Table 1 Important Logistics Metrics

\begin{tabular}{|c|l|c|l|}
\hline Sl.No & \multicolumn{1}{|c|}{ Metrics } & Sl.No & \multicolumn{1}{c|}{ Metrics } \\
\hline 1 & Shipping Time & 14 & Accurate order fulfilment \\
\hline 2 & Order Accuracy & 15 & Properly storing incoming product \\
\hline 3 & Delivery Time & 16 & Peaks in warehouse capacity \\
\hline 4 & Transportation Costs & 17 & Total cycle times \\
\hline 5 & Warehousing Cost & 18 & Damaged products \\
\hline 6 & Number of shipments & 19 & Employee turnover rate \\
\hline 7 & Inventory Accuracy & 20 & Accurate tracking of trailers \\
\hline 8 & Inventory Turnover & 21 & Recording Temperature \\
\hline 9 & Inventory to Sales Ratio & 22 & Total Logistics Cost \\
\hline 10 & On-time shipping & 23 & Incoming material quality \\
\hline 11 & Warehouse capacity & 24 & Line Item Fill Time \\
\hline 12 & Customer complaints & 25 & Labour utilization \\
\hline 13 & Overall Customer Satisfaction & 26 & Space vs Capacity of Plant \\
\hline
\end{tabular}

\subsection{Company Profile}

This study was conducted at Automotive Connection Systems Ltd., located in Kerala, India. This company is engaged in the manufacture and sale of automotive connectors, moulds, and tools for automotive connectors, and in design and engineering services. This is a subsidiary company of the parent companies located in France and USA. The Company has major technical centres, manufacturing sites and customer support facilities in 30 countries. The global market for connectors is around USD 35 billion. According to company's policy if a part is available with business units of the parent company then it has to be procured from there. About $96 \%$ of the total value has been purchased from their units (Inter-Unit Stock Transfer) and about $4 \%$ of the total value was purchased from other suppliers. This company handles 720 traded parts in their warehouse.

\section{LITERATURE REVIEW}

Literature review was conducted by analysing the related papers published in Emerald Publishing, Science Direct, Research Gate, Inderscience, IJPR, and Elsevier Journals. The articles published in this domain from 1989 to 2020(till date) are considered for analysis and the gap was identified. Very few studies were conducted on logistics performance measurements in warehouse scenario.

Three dimensions of firm performance that are most frequently used in business as well as supply chain research were summarise as accounting based, operational based and market based.

R.G. Kasilingam(2020) has stated that ability to measure is absolutely essential to design and or improve a logistic system or its components. Metrics should reflect the important working dimensions of business operations.

A. Gunasekaran, Patel. C, and McGaughey.R (2009) have highlighted the role of performance measurement and metrics in setting objectives, evaluating performance and determining future courses of actions. 
James S. Keebler and Richard E. Plank (2009) have studied the state of logistics performance measurement incorporations based in the USA. Most US firms do not comprehensively measure logistics performance. The focus continues to be on performance within the organization and not on performance between and across firms.

Sengottuvelu.C(2008) has measured supply chain performance by using SCOR level 123 metrics covering cycle time, cost, quality and assets metrics across five verticals viz. auto \& auto components, white goods, engineering, and electronics segments.

According to Gunasekaran and Kobu(2007), these dimensions capture the primary objectives from popular measurement stands such as the balanced scorecard as well as address the primary supply chain stakeholders. These stakeholders include shareholders measure on financial, suppliers who measure on operational, employees who measure on operational, competitors who measure on market and customers who measure on market.

Buyers. J, and Cole. M(1996) have studied and summarised the results of 24 metrics, used by the major US companies in the transportation and distribution functions.

Chow. G, Heaver T.D and Henrik Son(1994) studied the relationship between a given logistics strategy and performance.

According to P. Anderson, H.Aronsson and N.G.Storhagen(1989), the main objective in logistics should be overall coordination. The important measures are: productivity, lead time, quality, customer service, turnover ratio, cost estimating methods, mission costing, budgeting techniques etc.

\section{STATEMENT OF THE PROBLEM}

India's global ranking logistics performance index (LPI) was 3.18 and LPI rank 44 in 2018 (World Bank, 2018). As a country, this has to be improved. Logistics performance measures and metrics plays an important in achieving organization objectives. The right type of measures and metrics should be selected. The weakness of today's measuring systems often stems for a 'measurement gap' between the economists approach on measures of financial control and the engineer's approach, focussing on measuring physical quantities. This company is using some metrics as part of key performance indicators (KPI). In this study, 12important metrics covering cost metrics, cycle time metrics, productivity metrics and quality metrics were selected for analysis. Three years data were collected and analysis carried out.

\section{MAIN OBJECTIVES OF THE RESEARCH}

The key objectives of this study are:

- To analyse the logistical operations of a warehouse.

- To examine the various metrics commonly used in warehouse operations.

- To compare three years results in the selected metrics

- To identify the best practices adopted by the company.

\section{RESEARCH METHODOLOGY}

In this research, logistical operations of a warehouse have been studied. But the main focus was logistics performance measurement area. This company handles about 720 traded parts. Majority of the parts $(96 \%)$ comes from their intercompany basis and the remaining $4 \%$ of parts are procured from Indian suppliers. Three years data were collected from company's Management Information Report (MIR), annual returns \& published reports, interview conducted with senior managers and supervisors. MS Excel was used for data analysis. This 
company was having low inventory turnover ratio, high total logistics cost on sales, and high obsolete inventory. So, twelve important metrics were selected for performance measurements. Definition for each metrics was enclosed along with the data sheet more user friendly. This is the novelty and uniqueness of this research.

\section{MAJOR FINDINGS, RESULTS AND DISCUSSION}

Ten important metrics were selected and used for performance measurements. Three years data were collected for data analysis. The summaries of results are shown in table 2.

Table. 2 Summary of Results

\begin{tabular}{|c|l|c|c|c|}
\hline Sl.No. & \multicolumn{1}{|c|}{ Metrics } & Year 1 & Year 2 & Year 3 \\
\hline 1 & Sales to Logistics Cost (\%) & 7.75 & 8.08 & 8.88 \\
\hline 2 & Total Logistics Cost (Rs.in lakhs) & 1263.00 & 1376.00 & 1546.00 \\
\hline 3 & Inventory Turnover Ratio & 11.00 & 10.16 & 8.72 \\
\hline 4 & Order processed per labour unit & 11.22 & 12.86 & 14.58 \\
\hline 5 & Productive Hours to Total Available Hours (\%) & 83.00 & 86.00 & 88.00 \\
\hline 6 & On-Time Delivery (\%) & 99.00 & 99.15 & 99.06 \\
\hline 7 & Perfect Order Fulfilment (\%) & 98.00 & 98.00 & 98.00 \\
\hline 8 & Overall Customer Satisfaction (\%) & 98.46 & 97.97 & 96.08 \\
\hline 9 & Line Item Fill Timein hours & 3.0 & 3.0 & 2.0 \\
\hline 10 & Outbound Products Units Processed per Warehouse Labour & 23 & 30 & 58 \\
& Unit & & & \\
\hline 11 & Space Utilization vs Capacity of Plant (\%) & 82.66 & 83.10 & 87.00 \\
\hline 12 & Capacity of Warehouse vs Space Utilization (\%) & 90.00 & 89.00 & 92.00 \\
\hline
\end{tabular}

\subsection{Sales to Total Logistics Cost Metrics}

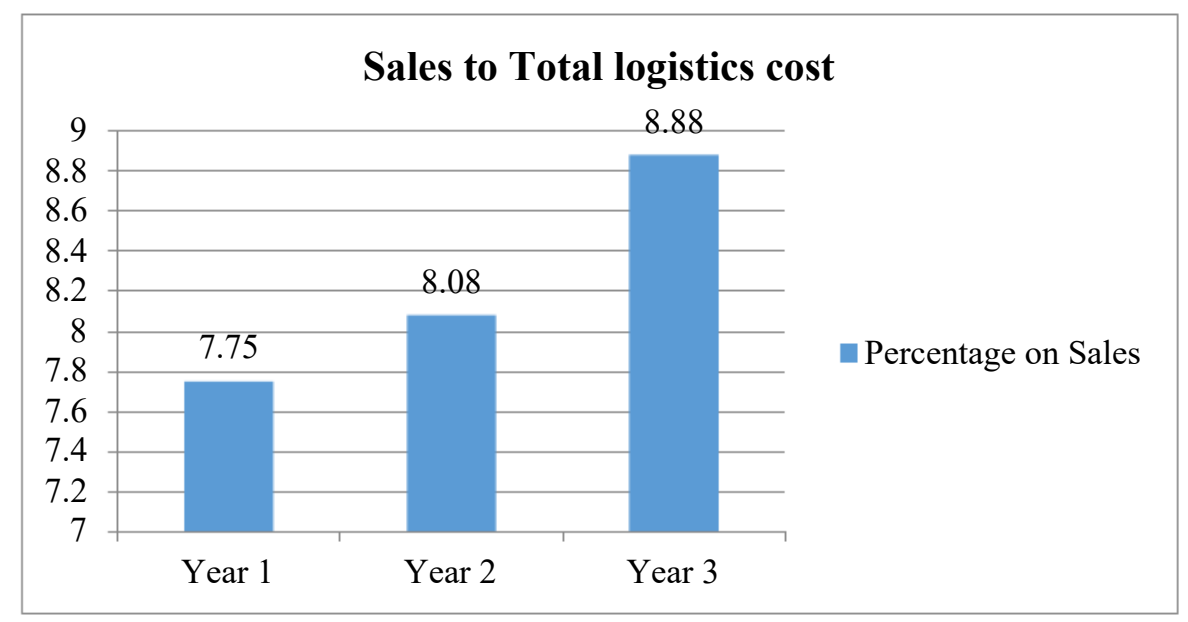

Chart 1 Sales to Total Logistics Cost Ratio

It is seen that there is an increase in total logistics cost from $7.75 \%$ to $8.90 \%$ keeping year 1 as base. 


\subsection{Total Logistics Cost}

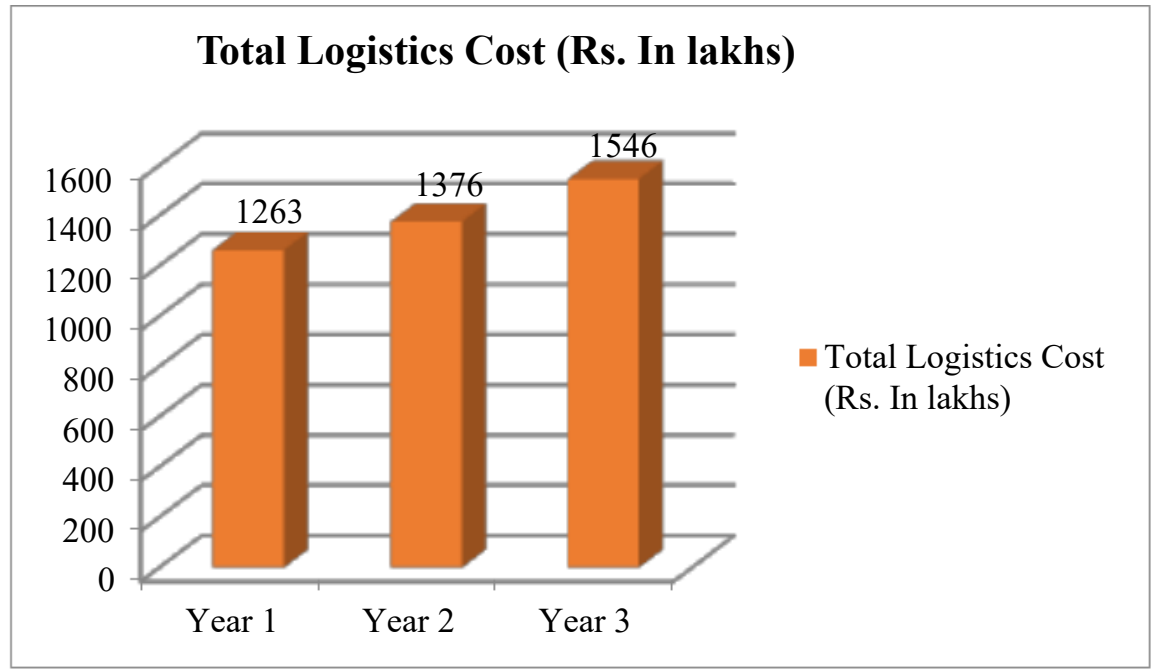

Chart 2 Total Logistics Cost

Total logistics cost includes outbound freight, inbound freight, $3{ }^{\text {rd }}$ Party storage cost and Inventory storage cost. It is seen that the total logistics cost incurred increase from Rs.1263 lakhs to Rs.1546 lakhs. Increase in inbound cost is the main reason for increase in total logistics cost.

\subsection{Inventory Turnover Ratio}

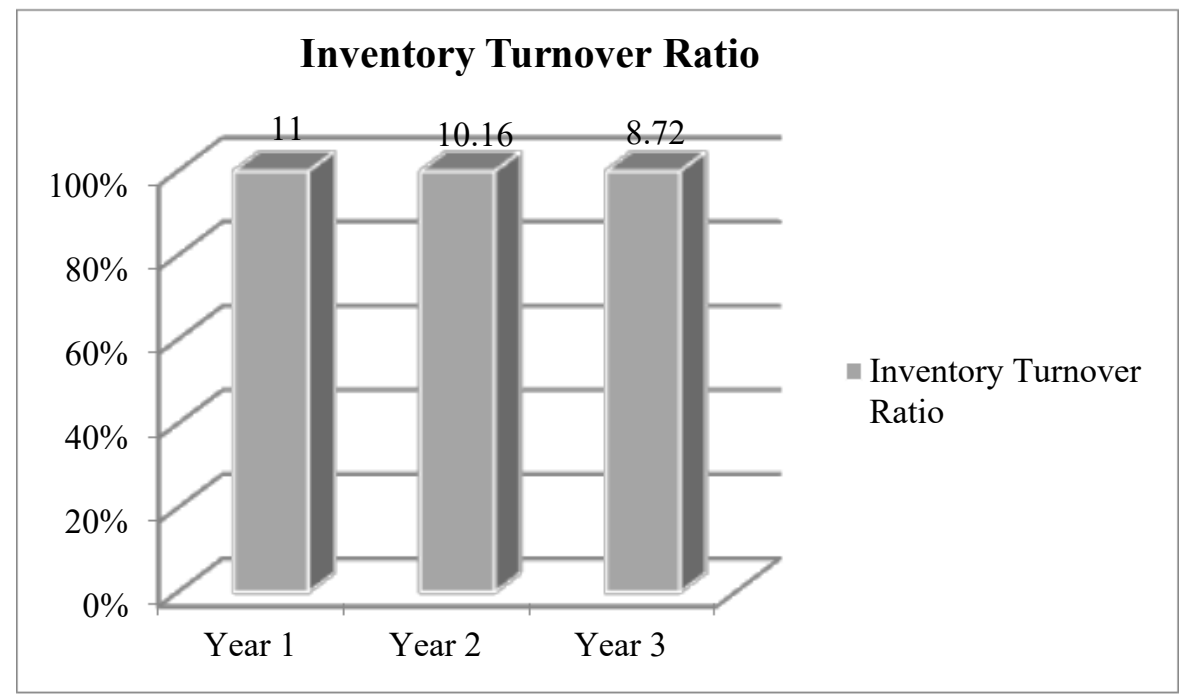

Chart 3. Inventory Turnover Ratio

It is seen that the inventory turnover ratio 11 times for year 1, 10.16 times for year and 8.72 times for year 3 . It means that the company's average inventory value is increasing year after year. 


\subsection{Order Processed Per Labour Unit}

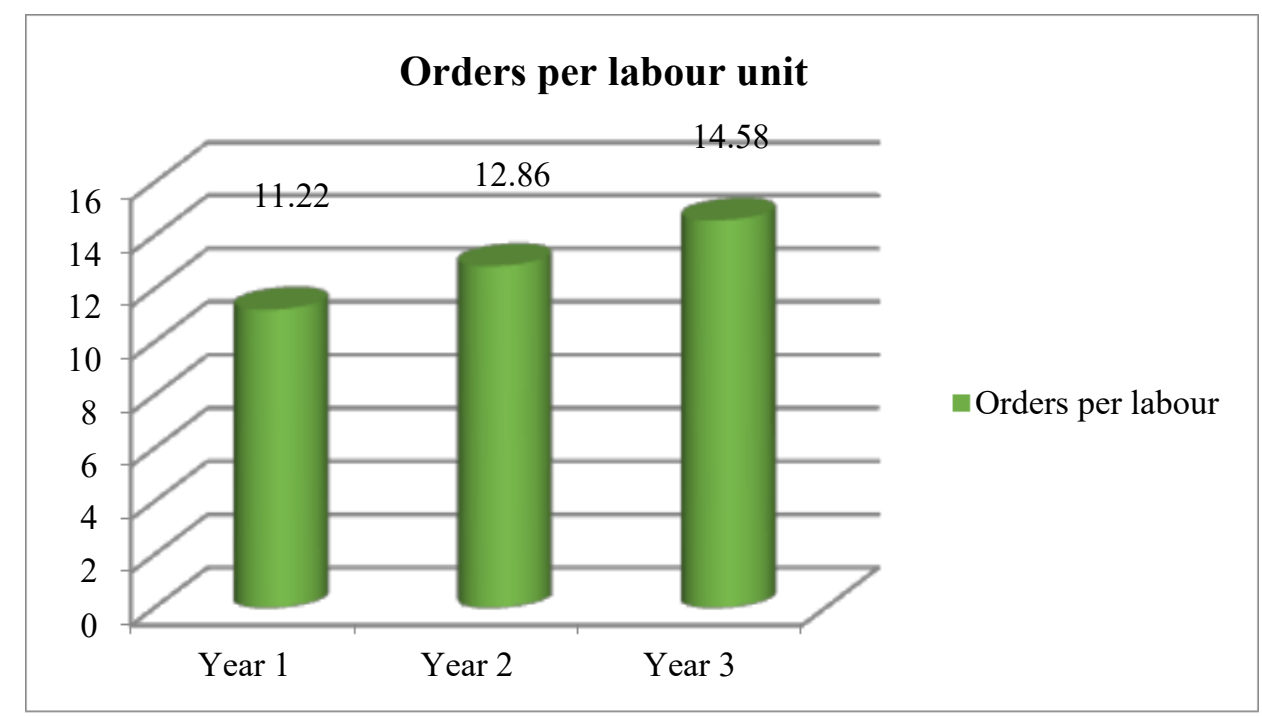

Chart 4 Order Processed Per Labour Unit

It is seen that order processed per labour unit 11.22 in year 1, 12.86 in year 2 and 14.58 in year 3, which shows that there is an increase in order processed per labour unit. .

\subsection{Productive Hours to Total Available Hours}

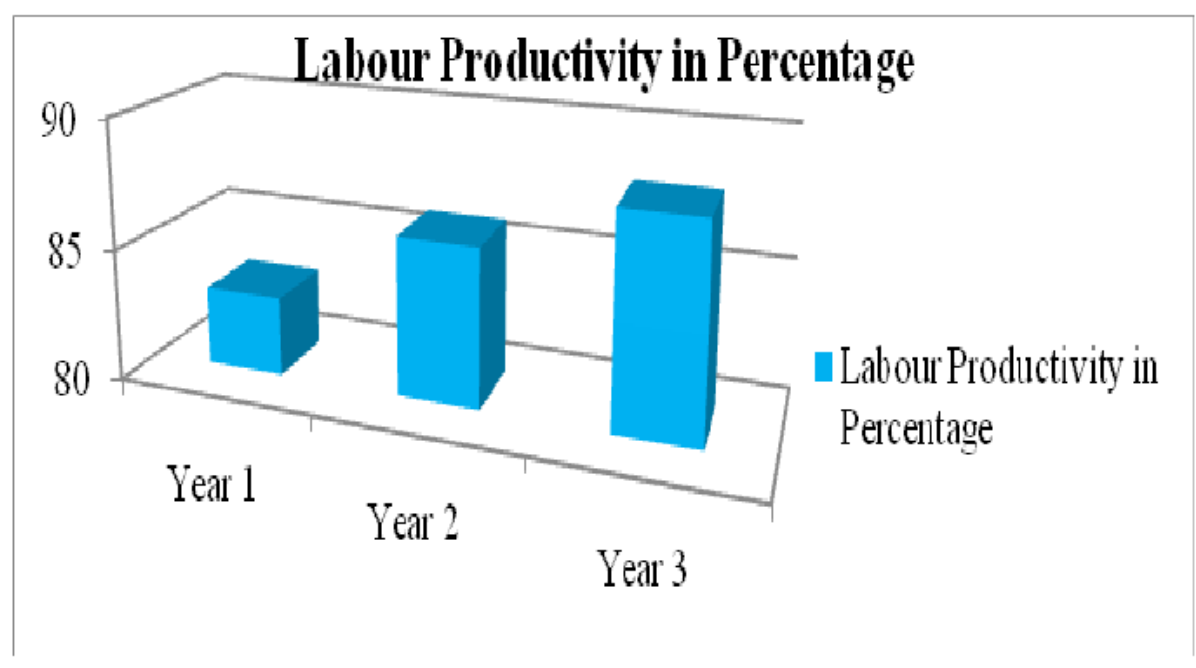

Chart 5. LabourProductivity

It is seen that the labour productivity in year $183 \%$, in year $286 \%$ and in year $388 \%$, which shows that there is an increase in labour productivity in the company.

\subsection{On-Time Delivery}

It is found that the company always maintains above $99 \%$ on-time delivery. This company is supplying traded parts to original equipment manufacturers (OEMs), where their assembly lines cannot start with shortage of parts. 


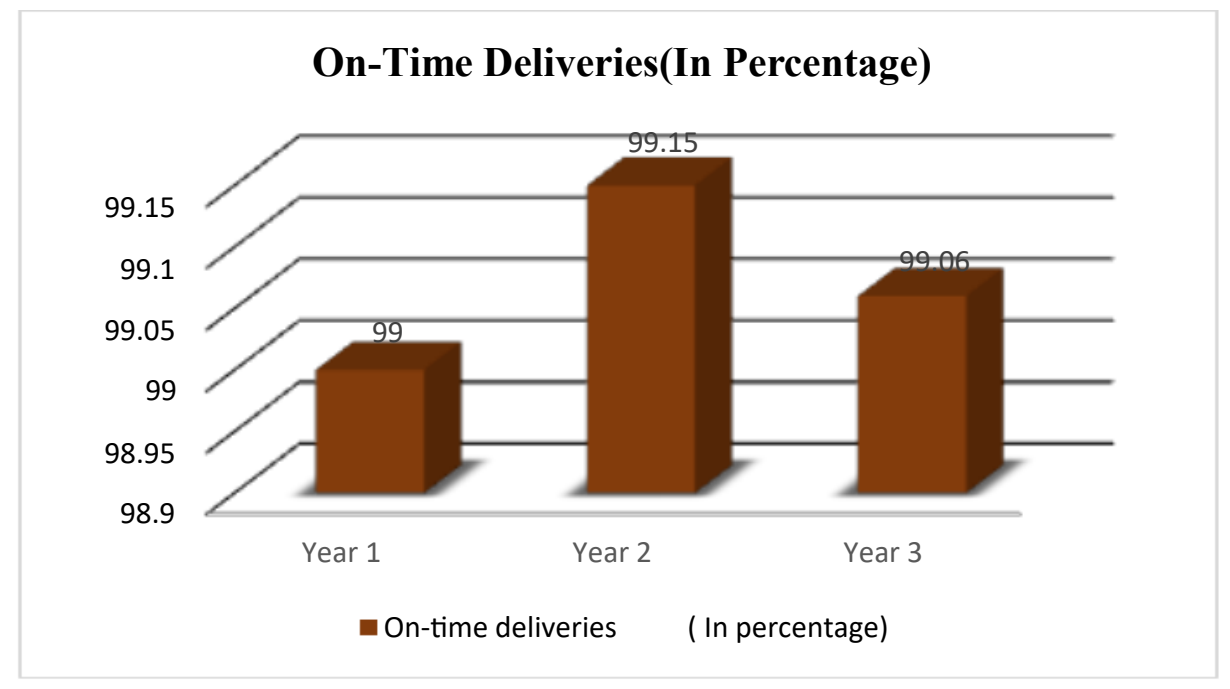

Chart 6. On-Time Delivery

\subsection{Perfect Order Fulfilment}

It is seen in table 2 that for all the three years company has $98 \%$ of perfect order fulfilment. That is the reason; there was only three complaints average with respect to logistics.

\subsection{Overall Customer Satisfaction}

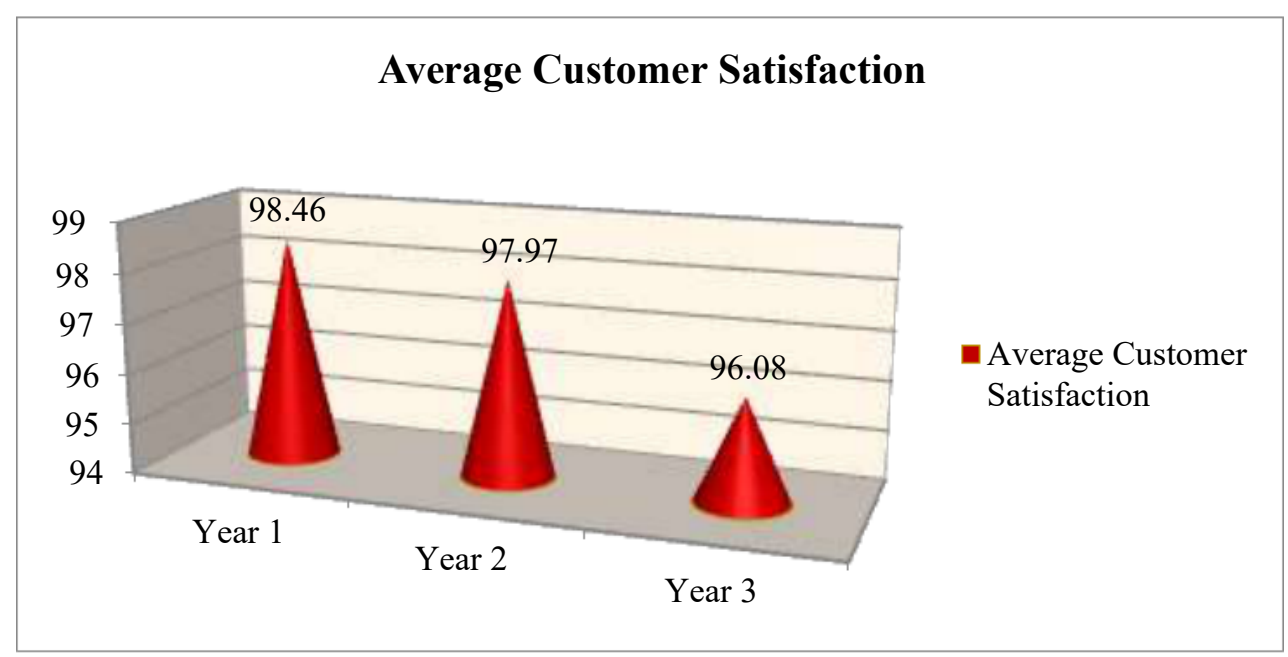

Chart 7. Average Customer Satisfaction

It is seen that this company maintains the $98.46 \%$ average customer satisfaction level in year $1,97.97 \%$ in year 2 and $96.08 \%$ in year 3 . This company has set a target on CSL as $85 \%$. So, they are able to achieve above the set standards. But, there is a decrease in CSL year after year. Therefore, the company should look these aspects seriously.

\subsection{Line Item Fill Time}

It is seen in table. 2 that the line item fill rate is 3 hours for year $1 \& 2$ and 2 hours for year 3. This is because has changed the warehouse layout by adopting lean methodologies recently. 


\subsection{Outbound Products Units Processed Per Warehouse Labour Unit}

It is seen in table 2 that the quantity processed in lakhs was 23 in year 1, 30 lakhs for year 2 and 58 lakhs units per labour for year 3 . It was also found that the number of pallets per labour were 266 for year 1, 390 for year 2 and 491 for year 3 .

\subsection{Space Utilization vs Capacity of Plant (\%)}

It is seen in table 2 that the company's space utilization rate was $82.66 \%$ for year $1,83.10 \%$ for year 2 and $87.00 \%$ for year 3. This is due to implementation of lean principles in their warehouse layout and operations.

\subsection{Capacity of Warehouse vs Space Utilization (\%)}

It is seen in table 2 that the warehouse space utilization was $90.00 \%$ in year $1,89.00 \%$ in year 2 and $92.00 \%$ in year3. It was found that this company should improve space utilization rate by redesigning the warehouse layout.

\section{CONCLUSION AND SCOPE FOR FURTHER RESEARCH}

In this study, the authors have highlighted the competitive priorities namely, price, quality, delivery, customer focus and know-how. The criteria delivery is the responsibility of logistics. In recent times companies are focusing on quick response, less lead time \& price, and quick last mile delivery (Amazon, DHL, FedEx, Flip kart, Blue Dart Express, OM Logistics etc) for gaining competitive advantage. The novelty of this study is in selecting the relevant metrics for performance measurements. Twelve important metrics were selected carefully and three years data analysed and compared. This has performed well in sales to total logistics cost, order processed per labour unit, productive hours to total available hours, on-time delivery, perfect and order fulfilment. Improvements are also noticed. This company should also give importance to some of metrics like inventory turnover ratio, overall customer satisfaction, total logistics cost, and capacity of warehouse vs space utilization. The company should set targets in all activities of logistics management on half yearly and annual basis. This company is yet adopting consolidation and collaboration strategies as part of their logistical operations. Lean principles are in the process of implementation in warehouse operations. The best practices should be maintained and continued to achieve sustainability in logistics management. There is enough scope available to conduct further research in areas like impact of lean practices and its outcomes in warehouse scenario. Influence of competitive priorities on gaining competitive advantage with reference logistical operations.

\section{ACKNOWLEDGEMENT}

The authors are grateful to managers and top management team for supporting this study. The help and support extended by the process and logistics control department is greatly acknowledged.

\section{REFERENCES}

[1] A. Gunasekaran, Patel. C, and McGaughey. R (2009). A framework for supply chain performance measurement. Internal Journal of Production Economics, Vol.87, Issue.3, pp.333-347.

[2] A.Gunasekaran and B.Kobu (2007). Performance Measures and Metrics in Logistics and Supply Chain Management: A Review of Recent Literature (1995-2004) for Research and Applications. International Journal of Production Research, Vol.45, Issue: 12, p.p. 28192840. 
Measuring Logistics Performance for Competitiveness - A Case Study of Automotive Connection Systems Company, Kerala, India

[3] A.S. Awwad, A.A.Alkhattaband J.R. Anchor (2013). Competitive Priorities and Competitive Advantage in Jordanian Manufacturing, International Journal of Services and Manufacturing, Vol. 6, No.1.

[4] Buyers. J, and Cole. M (1996). Logistics Metrics. Interim Research Report, Dept. of. Industrial Engineering, University of Arkansas, Fayetteville A.R.

[5] C.SengottuveluandMohd. Naved Khan (2008). Measuring supply chain performance in selected discrete manufacturing industries. AIMA Journal of Management \& Research, December 2008, Vol.2, Issue. 4/4. pp. 1-30.

[6] Chow. G, Heaver T.D and Henrik Son (1994). Logistics performance: Definition and Measurement. International Journal of Physical Distribution \& Logistics Measurement, Vol.24, No. 1, pp.17-28.

[7] D.J. Bloomberg, S.LeMay and J.B.Hanna (2005). Logistics.Upper Saddle River, NJ:

[8] Prentice Hall.

[9] J.J. Coyle, E.J.Bardi, and C.J. Langley Jr. (2006). The Management of Business Logistics, $8^{\text {th }}$ Edition, West Publishing Company, New York, pp.533-536.

[10] James S. Keebler and Richard E. Plank (2009). Logistics Performance Measurement in the supply chain: A Bench Mark. Benchmarking: An International Journal Vol.16, Issue.6.

[11] Logistics Costs and U.S Gross Domestic Product, Federal High Administration, Department of Transportation, MacroSys Research and Technology Washington, DC, August 25, 2005.

[12] Marshall Fisher (1997). What Is the Right Supply Chain for Your Product? Harvard Business Review, March-April, 1997.

[13] Martin Christopher (2003). Logistics and Supply Chain Management: Strategies for Reducing Cost and Improving Service, $3^{\text {rd }}$ Indian Edition, Pearson Education Asia, New Delhi, pp.2930 .

[14] Martin. J, Falk.S and Willibald. A.G, (2016). Logistics Performance Measurement System for the automotive industry. Logistics Research, Vol.9, Article No.11.

[15] N.GaitherandG.Frazier (2015). Operations Management: Concepts, Techniques \& Applications, ${ }^{\text {th }}$ Edition, South-Western Publishing Company. USA.

[16] P. Anderson, H.AronssonandN.G.Storhagen (1989). Measuring logistics performance. Engineering Costs and Production Economics, Vol. 17, Issue.1-4, p.p.253-262.

[17] Peter Drucker (1954). The Practice of Management. Collins Business Essentials, Kindle eTextbook Store, 2010.

[18] R.G. Kasilingam (2020). Logistics and Transportation: Design and Planning, Springer Nature, Springer Link, Switzerland A.G., pp. 213.

[19] Ridgway (1956). Dysfunctional Consequences of Performance Measurements. Collins Business Essentials, Kindle eTextbook Store, 2010.

[20] Sengottuvelu. C (2008). Measuring supply chain performance in selected FMCG and Manufacturing Industries, Ph.D. thesis submitted to Aligarh Muslim University, Aligarh, India.

[21] Sunil Chopra, Peter Meindle and D.V.Kalra (2013). Supply Chain Management - Strategy, Planning and Operation, $5^{\text {th }}$ Edition, Pearson Education Inc. New Delhi. pp. 29-31.

[22] Supply chain and logistics-Terms and Glossary updated February 2005 retrieved from www.csmp.org/downloads/resources/glossary on June 22, 2020.

[23] World Bank Global Logistics Ranking Survey 2018 Report retrieved from www.worldbank.org on June 22, 2020. 